\title{
A Magnetic Field Gradiometer based on the Laser Helium Optically Pumped Magnetic Field Sensors
}

\author{
Chao Wang, Zhijian Zhou, Defu Cheng and Jie Zhang* \\ College of Instrumentation and Electrical Engineering, Jilin University, Changchun, China \\ Received: March 18, 2020. Revised: April 10, 2020. 2nd Revised: May 13, 2020 \\ Accepted: June 26, 2020. Published: July 20, 2020.
}

\begin{abstract}
When the ratio of the background magnetic field value to the measured magnetic anomaly value is too large, it becomes very difficult for the surveyor to delineate and interpret the magnetic anomaly. Therefore, the measurement of magnetic gradient is particularly important. In this paper, a magnetic field gradiometer based on laser helium optically pumped magnetic sensors is developed. The main contents of the paper include:(1) operating principle of laser helium optically pumped magnetic sensor, (2) program of magnetic field gradiometer based on laser helium optically pumped magnetic sensors, (3) sensor laser source, (4) excitation technology of ${ }^{4} \mathrm{He}$ cell, (5) sensor magnetic signal detection technology. Finally, the performance of the magnetic field gradiometer is tested. The sensitivity of the two sensors was calculated to be $2.65 \mathrm{pT} / \mathrm{Hz}^{1 / 2} @ 1 \mathrm{~Hz}$ and $3.59 \mathrm{pT} / \mathrm{Hz}^{1 / 2} @ 1 \mathrm{~Hz}$ respectively. By comparing with the theoretical value of magnetic field and the data of Cs-3, it is proved that the gradiometer based on laser helium optically pump magnetometers has good practicability.
\end{abstract}

Keywords — gradiometer; laser; helium excitation; signal detection.

\section{INTRODUCTION}

$\mathrm{M}$ agnetic field is a basic physical quantity, which contains a lot of environmental information that cannot be observed directly. With the discovery of various magnetic phenomena in people's production and life, more and more attention has been paid to the measurement of magnetic field [1].

Laser optically pumped magnetic field sensor is a kind of high precision magnetic measuring instrument. The magnetic sensitive materials of these sensors mainly include alkali metal (rubidium, cesium, potassium, etc.) and helium. Compared with alkali metals, helium does not need to be heated and kept warm during the measurement process, thus consumes less power [2]. The fundamental physics of laser helium optically pumped magnetic field sensor are the Zeeman splitting and magnetic resonance (NMR) $[3,4]$.

In geophysical exploration, initially, surveyors were only concerned with the total magnetic field strength, which is what we call the magnetic field scalar value. Scalar values are isotropic and are fundamental properties of magnetic fields [5].
Due to the complexity of practical application scenarios and the increasing number of interference factors, the scalar value of the magnetic field will be annihilated in the magnetic field noise [6,7]. When the ratio of the background magnetic field value to the measured magnetic anomaly value is too large, it becomes very difficult for the surveyor to delineate and interpret the magnetic anomaly. But, if the gradient values are measured, the geomagnetic field and magnetic noise can be effectively filtered out to highlight the magnet under test. The total magnetic field gradient measurement makes the data types of magnetic detection more diversified, and it significantly improved the ability to obtain and analyze magnetic anomaly.

Nowadays, magnetic gradient measurement technology has been widely used in various fields of high precision magnetic measurement, including geophysical exploration, national defense and biomedicine $[8,9]$.

The foundation of total field gradient measurement is a high precision magnetic measuring instrument. Therefore, a magnetic field gradiometer based on laser helium optically pumped sensors is introduced in this paper. The program of gradiometer, laser source, excitation energy source of cell and signal detection technology were studied. Finally, the performance of the gradiometer is tested.

\section{OPERATING PRINCIPLE AND PROGRAM OF GRADIOMETER}

\section{A. Operating principle and sensitivity of optically pumped magnetic field sensor}

The helium optically pumped magnetic field sensor has a glass cell filled with ${ }^{4} \mathrm{He}$ atoms. In a magnetic field, ${ }^{4} \mathrm{He}$ atoms undergo the Zeeman effect, in which the Zeeman-splitted level formed according to the value of $\boldsymbol{M}$ (the magnetic quantum number of ${ }^{4} \mathrm{He}$ atoms). The energy interval between adjacent Zeeman-splitted level is proportional to the strength of the external magnetic field $\boldsymbol{B} \cdot \boldsymbol{1}^{\boldsymbol{l}} \boldsymbol{S}^{0}$ represents the ground state of ${ }^{4} \mathrm{He}$ atomic energy, $2^{3} S^{1}$ represents the metastable state of ${ }^{4} \mathrm{He}$ atomic energy, and $\mathbf{2}^{3} \boldsymbol{P}^{l}$ represents one of the excited states of ${ }^{4} \mathrm{He}$ atomic energy, as shown in Fig.1. ${ }^{4} \mathrm{He}$ atoms at $\boldsymbol{I}^{\boldsymbol{1}} \boldsymbol{S}^{\boldsymbol{0}}$ need to be stimulated by a discharge to cause collisions between electrons, absorbing energy in the process to jump to $2^{3} S^{I}$. ${ }^{4} \mathrm{He}$ atoms at $2^{3} S^{I}$ and $2^{3} \boldsymbol{P}^{1}$ are active [10-13].

Providing circularly polarized light to ${ }^{4} \mathrm{He}$ atoms, light energy induces ${ }^{4} \mathrm{He}$ atoms evenly distributed in $2^{3} S^{1}$ to transition to higher energy levels, the transition rule is $\Delta \boldsymbol{M}=\boldsymbol{+ 1}$, this phenomenon is called optical pumping. At the 
same time, due to relaxation, the ${ }^{4} \mathrm{He}$ atoms after transition will stay for a short time and then fall back to the lower energy level with equal probability. The transition between energy levels in two directions is cyclic, as shown in Fig.1. Finally, the optical pumping and relaxation achieve a dynamic equilibrium, with the ${ }^{4} \mathrm{He}$ atoms aligned in a magnetic direction $[13,14]$. This dynamic process is called the polarization of ${ }^{4} \mathrm{He}$ atoms. During polarization, ${ }^{4} \mathrm{He}$ atoms need to absorb light energy.

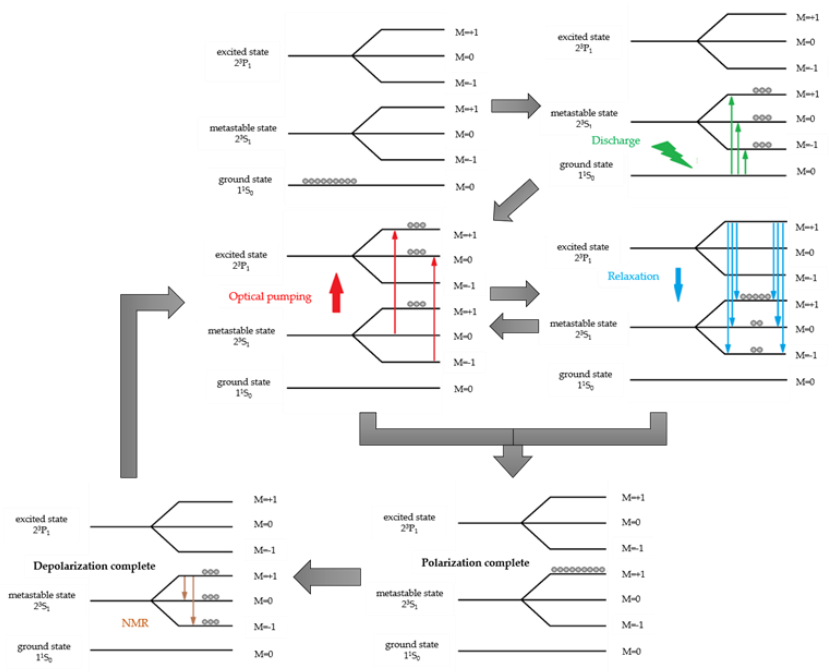

Fig. 1. Transitions in the process of atomic polarization and depolarization.

Helmholtz coil were used to apply alternating magnetic fields to ${ }^{4} \mathrm{He}$ atoms. When the frequency of the alternating magnetic fields is equal to the Larmor frequency, NMR occurs and the depolarization process is induced [15-17]. In the process of depolarization, transition between adjacent energy levels causes the magnetic moment of atoms to lose its orientation, as shown in Fig.1.

The intensity of light passing through ${ }^{4} \mathrm{He}$ atoms is monitored by photodetector. The signal produced by the photodetector is called the magnetic resonance signal. Depolarized ${ }^{4} \mathrm{He}$ atoms need to reabsorb light energy, so, we get the magnetic resonance point when the light intensity is the weakest.

The principle expression of magnetic field measurement is:

$$
B(n T)=\frac{v_{J}(H z)}{28.02356}
$$

Sensitivity is the fundamental index of sensor, usually, the sensitivity of optically pumped magnetic sensor is expressed by:

$$
\delta B=\frac{\Delta f}{\Delta S / N}
$$

$\Delta f$ is the resonance signal linewidth, which is the frequency difference between the maximum slope point and the minimums slope point in the signal curve. $\Delta S$ is the resonance signal amplitude. $\boldsymbol{N}$ is the noise power spectrum density of resonance signal.

\section{B. Program of gradiometer}

According to the operating principle, the magnetic field gradiometer based on laser helium optically pumped magnetic field sensors is a kind of precision instrument which integrates the design of optics, circuit and mechanical structure. The

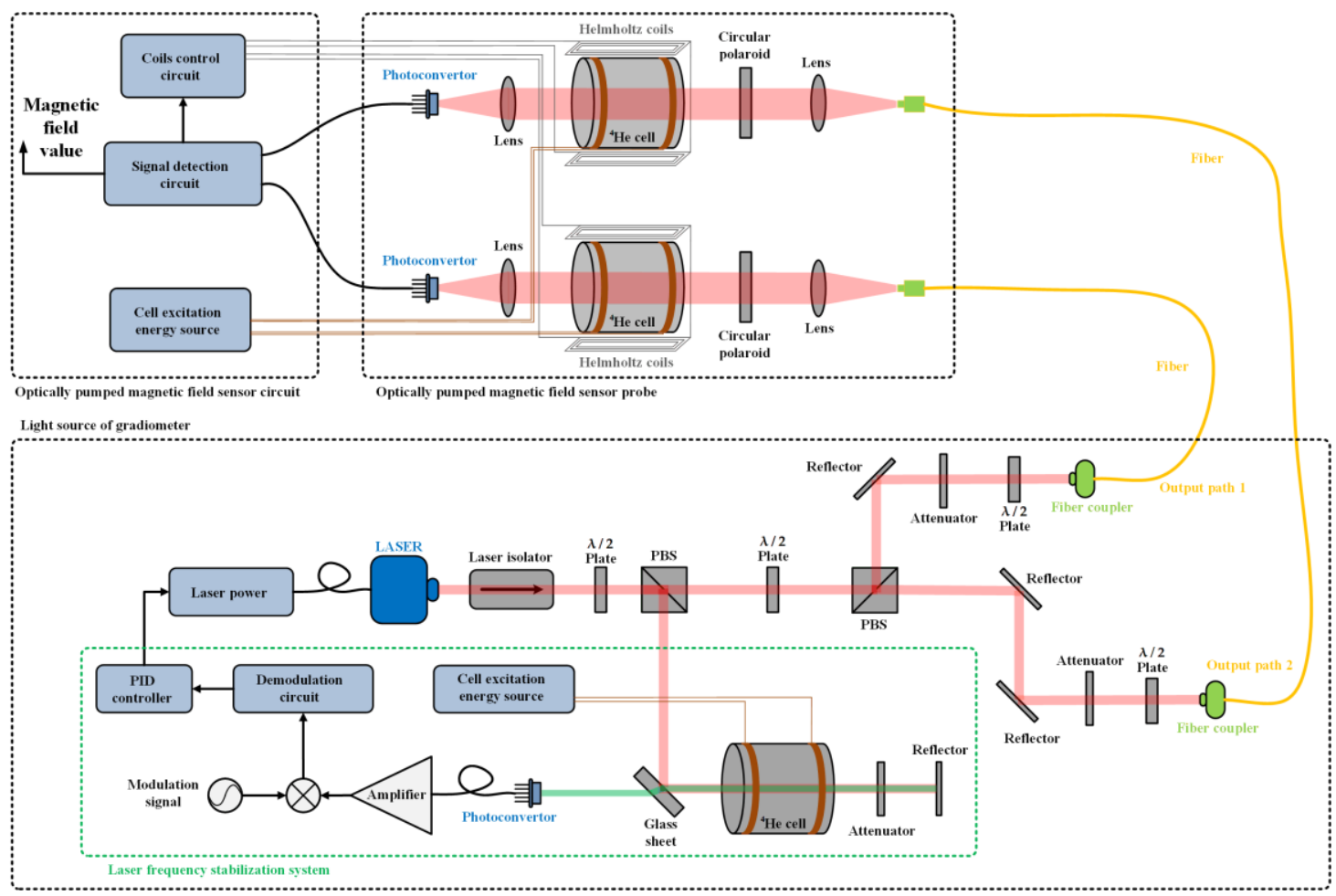

Fig. 2. Program of magnetic field gradiometer. 
program of magnetic field gradiometer is shown in Fig.2.

The magnetic field values measured by the two sensors are $\boldsymbol{B}_{\boldsymbol{A}}$ and $\boldsymbol{B}_{\boldsymbol{B}}$ respectively. The distance of the two sensors is $\boldsymbol{\Delta} \boldsymbol{L}$. The value of the gradient is (3).

$$
\frac{d B}{d L}=\frac{B_{A}-B_{b}}{\Delta L}
$$

The gradiometer mainly consists of laser light source, optically pumped magnetic field sensor probe and sensor circuit. The laser light source can be subdivided into laser power, laser frequency stabilization system, spectral optical path and coupling optical path. The optically pumped magnetic field sensor probe comprises ${ }^{4} \mathrm{He}$ cell, Helmholtz coils, absorption path and photoconverter. The sensor circuit includes the ${ }^{4} \mathrm{He}$ cell excitation energy source, the signal detection circuit and the coils control circuit.

\section{OPTICAL TECHNOLOGY OF GRADIOOMETER}

\section{A. Laser source and laser frequency stabilization system}

According the wavelength of transition line corresponding to ${ }^{4} \mathrm{He}$ atoms polarization, we select a DFB laser diode whose wavelength range covers $1083.207 \mathrm{~nm}$. The key factors influencing the wavelength of DFB laser include temperature and current $[13,18]$.

The influence of temperature on the laser wavelength is as follows:

$$
\lambda=\lambda_{0}+k_{1}\left(T-T_{0}\right)
$$

The influence of current on the laser wavelength is as follows:

$$
\lambda=\lambda_{0}+k_{2}\left(I-I_{0}\right)
$$

$\lambda(\mathrm{nm})$ is the theoretical wavelength of laser, $\lambda 0(\mathrm{~nm})$ is the central wavelength of laser, $\boldsymbol{k}_{\boldsymbol{1}}\left(\mathrm{nm} /{ }^{\circ} \mathrm{C}\right)$ is the tuning coefficient of temperature to wavelength, $\boldsymbol{k}_{2}(\mathrm{~nm} / \mathrm{mA})$ is the tuning coefficient of the current to wavelength, $\boldsymbol{T}\left({ }^{\circ} \mathrm{C}\right)$ is the actual temperature, $\boldsymbol{I}(\mathrm{mA})$ is the actual current, $\boldsymbol{T}_{\boldsymbol{0}}\left({ }^{\circ} \mathrm{C}\right)$ is the temperature threshold, $\boldsymbol{I}_{\boldsymbol{0}}(\mathrm{mA})$ is the current threshold.

EYP-DFB-1083-00080-1500-BFW01-0002 laser diode from Eagleyard company was selected. The main parameters were $\boldsymbol{k}_{1}=0.06 \mathrm{~nm} /{ }^{\circ} \mathrm{C}, \quad \boldsymbol{k}_{2}=0.003 \mathrm{~nm} / \mathrm{mA}, \quad \boldsymbol{T}_{0}=25^{\circ} \mathrm{C}, \quad \boldsymbol{I}_{0}=70 \mathrm{~mA}$, $\lambda_{0}=1083 \mathrm{~nm}$ at room temperature. According to (4) and (5), wavelength at $1083.207 \mathrm{~nm}$ needs $\boldsymbol{I} \approx 139 \mathrm{~mA}, \boldsymbol{T} \approx 28.45^{\circ} \mathrm{C}$.

As shown in Fig.2, a closed-loop feedback system based on the saturated absorption spectrum of ${ }^{4} \mathrm{He}$ atoms was constructed to stabilize the laser frequency. The glass sheet, attenuator and reflector cause the laser beams that shoot into the ${ }^{4} \mathrm{He}$ cell in opposite directions but take roughly the same path. Mixing the photoconverter signal and the sine modulation signal. Differential error signal is obtained by phase-locked amplification, filters, and demodulators. Then the PID regulator adjusts the differential error signal to the appropriate feedback gain and sends it back to the laser power to stabilize the laser frequency.

Also as shown in Fig.2, laser beam passes through the laser isolator, it splits into two parts via $\lambda / 2$ plate and PBS
(Polarization Beam Splitter). One beam is applied to the saturation absorption spectrum, another beam bundle splits again, through $\lambda / 2$ plate and PBS. The rotatable $\lambda / 2$ plate and attenuator can adjust the laser intensity. The laser beams through the $\lambda / 2$ plate are linearly polarized light, and they are coupled into a single-mode polarization-preserving fiber for output.

The theoretical maximum output power of DFB laser diode selected for the light source is $90 \mathrm{~mW}$. The laser isolator was selected from Thorlabs IO-5-1083-VLP, and its forward transmission efficiency was about $92 \% . \lambda / 2$ plate was selected from Thorlabs WPV10-1083, and its forward transmission efficiency is greater than $96 \%$. PBS was selected from Thorlabs PBS053, and its transmission efficiency was more than $90 \%$, reflection efficiency was more than $99.5 \%$. Therefore, the theoretical maximum power value of the beam before the second splitting is $\boldsymbol{P}_{\boldsymbol{t}}=90 \square 92 \% 96 \% 90 \% \square 6 \% \approx 68 \mathrm{~mW}$. Since the transmission and reflection efficiency of the PBS are different, the two beams after splitting also have power deviation. By rotating the attenuator, the power of two beams can be ensured to be consistent.

According to the light path shown in Fig.2, the anti-vibration mechanical structure shown in Fig.3(a) was designed. Non-magnetic pure aluminum was used, and the size of light source is $50 \mathrm{~cm} * 40 \mathrm{~cm} * 15 \mathrm{~cm}$ (length * width $*$ height), the weight is about $15 \mathrm{~kg}$.

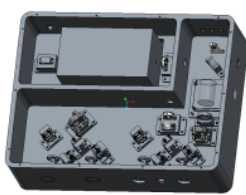

(a)

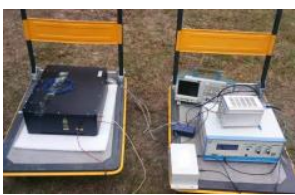

(b)

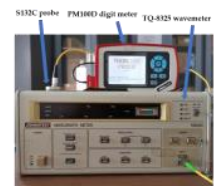

(c)
Fig. 3. (a) Light source structure design. (b) Performance test of light source outdoor. (c) Light source testing equipment

TABLE I. Partial parameters of the beam

\begin{tabular}{c|c|c}
\hline Power adjusTABLE range & $1 \mathrm{~mW}--23 \mathrm{~mW}$ & $1 \mathrm{~mW}---21 \mathrm{~mW}$ \\
\hline Power fluctuation range & $< \pm 0.01 \mathrm{~mW}$ & $< \pm 0.01 \mathrm{~mW}$ \\
\hline $\begin{array}{c}\text { Power fluctuation } \\
\text { percentage error }\end{array}$ & $<20 \% \mathrm{o}$ & $<20 \% \mathrm{o}$ \\
\hline $\begin{array}{c}\text { Central value of wavelength } \\
\text { Wavelength fluctuation }\end{array}$ & $1083.207 \mathrm{~nm}$ & $1083.207 \mathrm{~nm}$ \\
\hline $\begin{array}{c}\text { Wavelength fluctuation } \\
\text { percentage error }\end{array}$ & $<0.001 \mathrm{~nm}$ & $< \pm 0.001 \mathrm{~nm}$ \\
\hline
\end{tabular}

The finished light source and its outdoor test status are shown in Fig.3(b). The beam quality of the light source is measured by the wavemeter and optical power meter, the test equipment is shown in Fig.3(c). Partial parameters of the beam are shown in TABLE $\mathbf{I}$.

The measured optical power range of output path 1 is $1 \mathrm{~mW}-23 \mathrm{~mW}$, the optical power range of output path 2 is $1 \mathrm{~mW}--21 \mathrm{~mW}$. The actual difference between transmission and 
reflection efficiency of the PBS is about $4.5 \%$, which is meet design expectations. The efficiency of the coupler, $\boldsymbol{\eta}=(21+23) / 68 \approx 65 \%$, also meeting the design expectations. Within 30 minutes, the optical power fluctuation of both output beams was less than $\pm 0.01 \mathrm{~mW}$, the percentage error of optical power fluctuation within the adjustable power range shall not exceed 20\%. Within 30 minutes, the wavelength fluctuation was less than $\pm 0.001 \mathrm{~nm}$, and the percentage error of wavelength fluctuation was less than $0.002 \%$.

The laser light source is powered by $\pm 18 \mathrm{~V}$ DC power supply. When it works stably, the positive power supply current is about $300 \mathrm{~mA}$, the negative power supply current is about $200 \mathrm{~mA}$, and the overall power consumption is about $9 \mathrm{~W}$.

\section{B. Structure design of sensor probe}

The beam output by single-mode polarization-maintaining fiber is linearly polarized light with divergence Angle, therefore, it is necessary to collimate the beam first in the optical path of magnetic sensor probe. After collimating, the beam is transformed into circularly polarized light by circular polaroid.

The optical path design of the magnetic sensor probe is shown in Fig.2. The light beam is collimated by a convex lens, and finally focused by a convex lens into the photoconverter. The lens was selected from Thorlabs LA252-C, with a focal length of $25.4 \mathrm{~mm}$. Circular polaroid was selected from Thorlabs CP1L-1083-SP. Using PLA (polylactide) material, 3D printing technology was used to make the non-magnetic magnetic sensor. In the manufacture of sensors, the optical elements should be coaxial, the fiber output joint and photodiode photosensitive surface should be placed near the focal point of the lens.

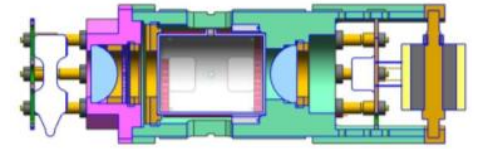

(a)

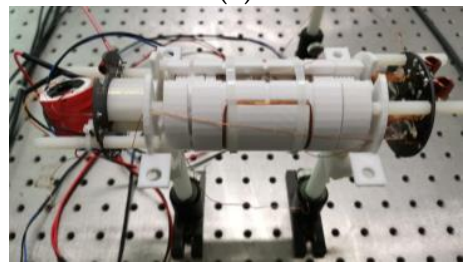

(c)

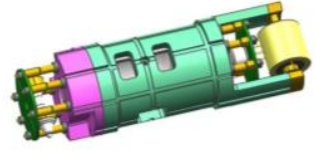

(b)

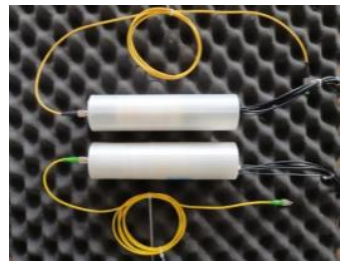

(d)
Fig. 4. (a) (b) Structure design of magnetic sensor probe. (c) The inner structure of probe. (d) The completed probes

The structure design of the magnetic sensor probe is shown in Fig.4 (a) and Fig.4 (b). The inner structure of the probe is shown in Fig.4 (c). The completed dual-channel magnetic sensor probes are shown in Fig.4 (d). The probe is cylindrical in shape, with a diameter of $54 \mathrm{~mm}$, a length of $200 \mathrm{~mm}$ and the weight of a single probe is about $1 \mathrm{~kg}$.

\section{EXCITATION ENERGY SOURCE OF ${ }^{4} \mathrm{HE}$ CELL}

\section{A. Program of excitation energy source}

The cell is a cylindrical sealed glass chamber filled with ${ }^{4} \mathrm{He}$. Since ${ }^{4} \mathrm{He}$ is an inert gas, the cell needs to accept the energy to make the ${ }^{4} \mathrm{He}$ atoms in the ground state jump to metastable state. After transition, ${ }^{4} \mathrm{He}$ atoms have "activity" to make magnetic measurements. This process of activating ${ }^{4} \mathrm{He}$ atoms in the cell is called the excitation.

According to the gas discharge theory, the initial state of ${ }^{4} \mathrm{He}$ atom in the excitation process belongs to the non-self-sustaining discharge, while the stable state belongs to the self-sustaining discharge. The phenomenon of the transition from the non-self-sustaining discharge to the self-sustaining discharge is called the breakdown of the gas $[19,20]$. The breakdown happens instantaneously if the ${ }^{4} \mathrm{He}$ atoms gain a lot of energy instantaneously. Once in a self-sustaining state, ${ }^{4} \mathrm{He}$ atoms need only a small amount of energy to sustain the discharge. Therefore, the design scheme of the excitation energy source of ${ }^{4} \mathrm{He}$ cell is shown in Fig.5.

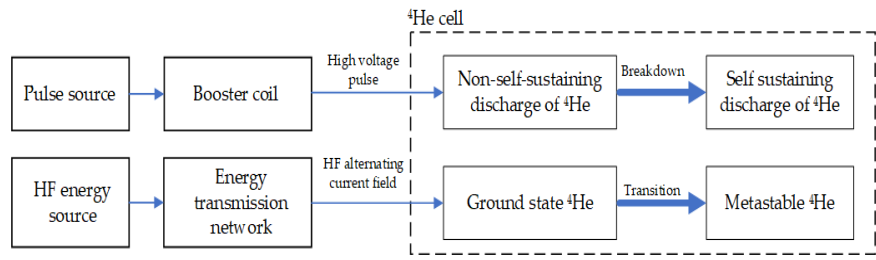

Fig. 5. Program of the ${ }^{4} \mathrm{He}$ cell excitation energy source

The high voltage pulse caused a huge voltage difference between the two external electrodes over the cell instantaneously. After the voltage difference exceeds the breakdown threshold, ${ }^{4} \mathrm{He}$ is broken down and enters the self-sustaining discharge state, then, the cell presents stable resistance characteristics. Meanwhile, HF energy source provides an alternating current field to the cell by another set of external electrodes, providing the energy needed to sustain the self-sustaining discharge of ${ }^{4} \mathrm{He}$. The energy transmission network can match the impedance between the energy source and cell to ensure the high energy transmission efficiency.

\section{B. High voltage excitation technology}

According to Paschen law [21], the product of ${ }^{4} \mathrm{He}$ pressure $\boldsymbol{P}_{\boldsymbol{H} \boldsymbol{e}}$ and discharge gap $\boldsymbol{d}_{\boldsymbol{H} \boldsymbol{e}}$ can be drawn as Paschen curve with ${ }^{4} \mathrm{He}$ breakdown voltage $\boldsymbol{V}_{\boldsymbol{H e}}$. When the value of $\boldsymbol{P}_{\boldsymbol{H e}}\left[\boldsymbol{d}_{\boldsymbol{H e}}\right.$ is small, $\boldsymbol{V}_{\boldsymbol{H e}}$ decreases exponentially with the increase of $\boldsymbol{P}_{\boldsymbol{H e}} \boldsymbol{d}_{\boldsymbol{H e}}$. When the value of $\boldsymbol{P}_{\boldsymbol{H}} \boldsymbol{d}_{\boldsymbol{H e}}$ is large, $\boldsymbol{V}_{\boldsymbol{H} \boldsymbol{e}}$ increases slowly and linearly with the increase of $\boldsymbol{P}_{\boldsymbol{H e}} \boldsymbol{d}_{\boldsymbol{H e}}$. The intersection of two curves is called the minimum breakdown voltage. According to the data, when $\boldsymbol{P}_{\boldsymbol{H e}}\left[\boldsymbol{d}_{\boldsymbol{H e}}=533.3 \mathrm{~cm} / \mathrm{Pa}\right.$, the minimum breakdown voltage of ${ }^{4} \mathrm{He}$ is $156 \mathrm{~V}$.

The cell is cylindrical, about $4 \mathrm{~cm}$ in diameter and $5 \mathrm{~cm}$ in length, with a ${ }^{4} \mathrm{He}$-filled pressure of about $100 \mathrm{~Pa}$. The external high-voltage electrode was installed symmetrically at both ends of the cell, and the distance between them, namely the discharge gap, was about $3 \mathrm{~cm}$. The $\boldsymbol{P}_{\boldsymbol{H e}}\left\lceil\boldsymbol{d}_{\boldsymbol{H e}}\right.$ of cell is about 
$300 \mathrm{~cm} / \mathrm{Pa}$, and the breakdown voltage of ${ }^{4} \mathrm{He}$ in the cell is estimated to be about $1.5 \mathrm{kV}$ based on the Paschen curve.

A tunable pulse source based on multivibrator and booster coil is designed. With trigger switch control, the pulse source provides a transient periodic pulse for cell. The circuit design is shown in Fig.6.

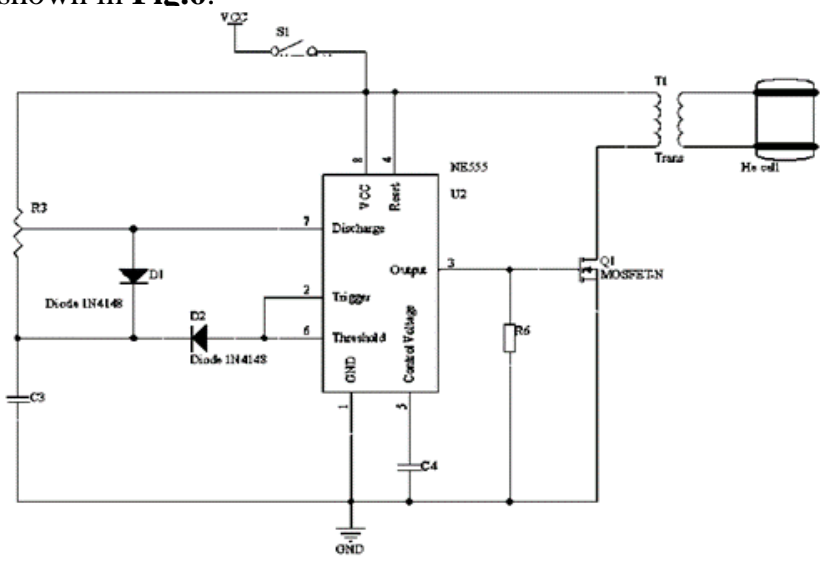

Fig.6. High voltage pulse source based on multivibrator

$\boldsymbol{R}_{3}$ and $\boldsymbol{C}_{3}$ can adjust the period of pulse output of the oscillator. $\boldsymbol{R}_{\mathbf{3}}$ can be equivalent to resistance $\boldsymbol{R}_{\boldsymbol{1}}$ in series between $\boldsymbol{D}_{1}$ and the power supply, and $\boldsymbol{R}_{2}$ in parallel with $\boldsymbol{D}_{2}$. When the power is switched on, the current is charged through $\boldsymbol{R}_{1}$ to $\boldsymbol{C}_{3}$, when the power is disconnected, $\boldsymbol{C}_{2}$ discharges through $\boldsymbol{R}_{2}$. Suppose the pulse duty cycle is $\boldsymbol{Q}_{0}$, then:

$$
Q_{0}=\frac{R_{1} C_{3}\lfloor\ln 2}{R_{1} C_{3} \ln 2+R_{2} C_{3} \backslash \ln 2}=\frac{R_{1}}{R_{1}+R_{2}}
$$

The $\mathrm{V}_{\mathrm{pp}}$ of the pulse voltage are consistent with the supply voltage, is $12 \mathrm{~V}$. The pulse is fed into the booster coil after power amplification. Since the ${ }^{4} \mathrm{He}$ breakdown voltage in cell is about $1.5 \mathrm{kV}$, and in order to reduce the adverse effect on the magnetic measurement, a hollow boost coil with a ratio of primary to secondary turns which is 20:12000 was designed. For the same reason, the pulse frequency should be as far away as possible from the modulation frequency of Helmholtz coils. The pulse frequency is set to $20 \mathrm{kHz}$ when $\boldsymbol{R}_{3}=2 \mathrm{k} \Omega$ and $C_{3}=36 \mathrm{nF}$.

TINA software developed by Texas Instruments was used to simulate the multivibrator. According to (5), when the ratio of $\boldsymbol{R}_{1}$ and $\boldsymbol{R}_{2}$ is $1: 9$, the duty cycle of the periodic pulses is about $10 \%$, the simulation result is shown in Fig.7(a), frequency of signal is about $20 \mathrm{kHz}$. The measured waveform of circuit is shown in Fig.7(b), the duty cycle of the signal is about $9.05 \%$, and the frequency is about $20.67 \mathrm{kHz}$. The high voltage pulse source is in line with the design expectation.

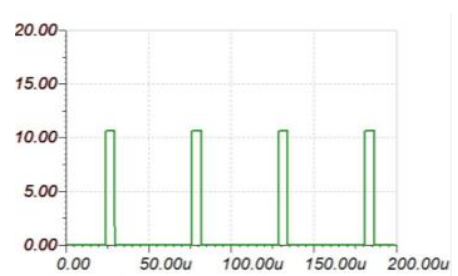

(a)

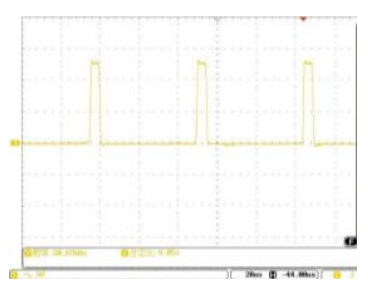

(b)
Fig.7. (a) Simulation result of TINA. (b) Measured waveform

\section{High frequency excitation technology}

The ${ }^{4} \mathrm{He}$ cell is connected to the excitation circuit by coaxial cable. Therefore, it is necessary to design a HF energy source circuit with MOSFET power amplifier, and an impedance matching network. Drawing on the experience in the field of gas discharge lamp [19,20], a 50MHz HF energy source program was designed, as shown in Fig.8.

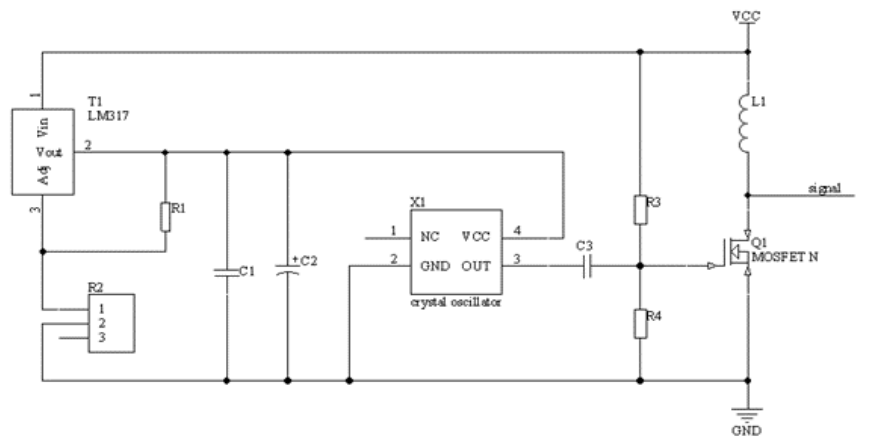

Fig.8. HF energy source circuit

The constant temperature crystal oscillator provides a stable $50 \mathrm{MHz}$ output. The common source amplifier is designed by using MOSFET. The partial voltage offset circuit composed of $\boldsymbol{R}_{\mathbf{3}}$ and $\boldsymbol{R}_{\mathbf{4}}$ can provide the appropriate gate source voltage $\boldsymbol{V}_{G S}$ for the MOSFET. Select MITSUBISHI RD06HVF1 high frequency MOSFET, whose on voltage $V_{T}=4 \mathrm{~V}$, the circuit operating voltage $\boldsymbol{V} c \boldsymbol{c}=12 \mathrm{~V}$. When the values of $\boldsymbol{R}_{\mathbf{3}}$ and $\boldsymbol{R}_{\mathbf{4}}$ are $2 \mathrm{k} \Omega$ and $1 \mathrm{k} \Omega$ respectively, $\boldsymbol{V}_{G S}=8 \mathrm{~V}>\boldsymbol{V}_{T}$, and the MOSFET can work in the saturated region. The common source power amplifier belongs to class $\mathrm{A}$ power amplifier according to the characteristics of the circuit during the waveform cycle.

MOSFET is a voltage control device. In the saturation region, the drain output current $\boldsymbol{i}_{D}$ and the gate source voltage $\boldsymbol{V}_{\boldsymbol{G S}}$ show a linear relationship within a certain range. Therefore, the HF energy source shown in Fig.9 is a single-port output network. Typical output power of RD6HVF1 is $6 \mathrm{~W}$, circuit power supply $\boldsymbol{V c c}=12 \mathrm{~V}$, saturation tube pressure drops $\boldsymbol{V}_{\boldsymbol{d} s \boldsymbol{s}} \approx 1 \mathrm{~V}$. According to the maximum power transfer theorem, the load impedance of the maximum output power can be estimated:

$$
R_{L s}=\frac{U_{R_{L} m}^{2}}{2 P_{\text {omax }}}=\frac{\left(V_{c c}-V_{d s s}\right)^{2}}{2 P_{\text {omax }}}=\frac{(12-1)^{2}}{2 \llbracket 6} \approx 10 \Omega
$$

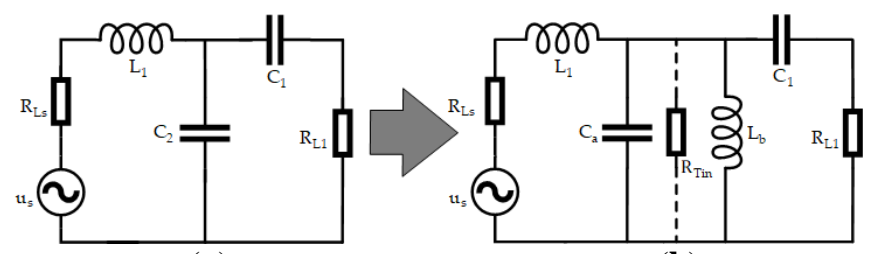

(a)

(b)

Fig.9. (a) The T-network design of energy transmitter circuit. (b) 
The double L-network equivalent model of T-network.

In the actual process of circuit preparation, the choice of capacitor is simpler than that of inductor, and the error control of capacitor is better than that of inductor. Therefore, the use of inductance should be minimized in circuit design. Design the impedance matching T-network as shown in Fig.9(a). $\boldsymbol{C}_{2}$ in the circuit can be divided into two parallel components $\boldsymbol{C}_{\boldsymbol{a}}$ and $\boldsymbol{L}_{\boldsymbol{b}}$, T-network can be equivalent to a double L-network model, and an imaginary resistor $\boldsymbol{R}_{\text {Tin }}$ is inserted in the middle [22]. The double L-network equivalent model is shown in Fig.9(b).

According to (7), the T-network source impedance is $\boldsymbol{R}_{L S}=10 \Omega$. Since the coaxial cable impedance is $50 \Omega$, the load impedance is $\boldsymbol{R}_{\boldsymbol{L I}}=50 \Omega, \boldsymbol{R}_{\boldsymbol{L} \boldsymbol{I}}>\boldsymbol{R}_{\boldsymbol{L}}$. The matching conditions are $\boldsymbol{R}_{\text {Tin }}>\boldsymbol{R}_{L s}$ and $\boldsymbol{R}_{\text {Tin }}>\boldsymbol{R}_{L 1}$. In Fig.9(b), the quality factor of L-network nodes composed of $\boldsymbol{L}_{\boldsymbol{l}}$ and $\boldsymbol{C}_{\boldsymbol{a}}$ is defined as $Q_{T 1}$, the quality factor of L-network nodes composed of $\boldsymbol{L}_{b}$ and $\boldsymbol{C}_{1}$ is defined as $\boldsymbol{Q}_{T 2}$, then:

$$
\begin{aligned}
& Q_{T 1}=\sqrt{\frac{R_{T i n}}{R_{L s}}-1} \\
& Q_{T 2}=\sqrt{\frac{R_{T i n}}{R_{L 1}}-1}
\end{aligned}
$$

The passband width of T-network is determined by $\boldsymbol{Q}_{T I}$ and $\boldsymbol{Q}_{T 2}$. Since $\boldsymbol{R}_{L 1}>\boldsymbol{R}_{L s}$, so $\boldsymbol{Q}_{T 1}>\boldsymbol{Q}_{T 2}$, it is necessary to select $Q_{T 1}$ to calculate the parameters from the source impedance. The on-load quality factor of the circuit is $Q_{T L}=Q_{T 1} / 2$, the $3 \mathrm{~dB}$ passband width of T-network is:

$$
B W_{T 0.7} \approx \frac{f_{0}}{2 Q_{T L}}
$$

After calculation, it can be obtained that:

$$
\begin{gathered}
\boldsymbol{R}_{T i n}=\left(1+Q_{T 1}^{2}\right) \boldsymbol{R}_{L s} \\
L_{1}=Q_{T 1} \square R_{L s} \\
C_{1}=Q_{T 2} \square R_{L 1}
\end{gathered}
$$

Since $\boldsymbol{C}_{a}$ and $\boldsymbol{L}_{b}$ are in parallel to form $\boldsymbol{C}_{2}$, and there are $C_{a}=R_{T i n} / Q_{T 1}, L_{b}=R_{T i n} / Q_{T 2}$, so:

$$
C_{2}=\frac{\left.\left\lfloor\left(1+Q_{T 1}^{2}\right) R_{L s} / Q_{T 1}\right\rfloor\left(1+Q_{T 1}^{2}\right) R_{L s} / Q_{T 2}\right\rfloor}{\left(1+Q_{T 1}^{2}\right) R_{L s} / Q_{T 1}+\left(1+Q_{T 1}^{2}\right) R_{L s} / Q_{T 2}}
$$

The T-network has the function of frequency selection. According to the definition of narrow-band filter, the target $3 \mathrm{~dB}$ passband width of T-network is set to $2.5 \mathrm{MHz}$. Substitute the data into (8) to (14) for calculation. Ideally, $\boldsymbol{L}_{\boldsymbol{l}}=636.62 \mathrm{nH}$, $\boldsymbol{C}_{\boldsymbol{l}}=7.15 \mathrm{pF}, \boldsymbol{C}_{\boldsymbol{a}}=15.9 \mathrm{pF}, \boldsymbol{L}_{\boldsymbol{b}}=1434 \mathrm{nH}$.

Agilent's ADS (Advanced design System) was used to conduct simulation experiments. In the simulation experiment,
$\mathrm{S}$ parameter is used to measure the performance of matching network. Ideally, because $\mathbf{2} \boldsymbol{\pi} f_{0} \boldsymbol{C}_{\boldsymbol{a}}>\boldsymbol{1} / \mathbf{2} \boldsymbol{\pi} \boldsymbol{f}_{\boldsymbol{0}} \boldsymbol{L}_{\boldsymbol{b}}$, the parallel circuits of $\boldsymbol{C}_{a}$ and $\boldsymbol{L}_{b}$ are capacitive, and $\boldsymbol{C}_{2}=8.815 \mathrm{pF}$ is obtained through design optimization. The simulation results are shown in Fig.10. At 50MHz, $\boldsymbol{S}_{11}=-66.232 \mathrm{~dB}, \boldsymbol{S}_{21}=0 \mathrm{~dB}$, and $3 \mathrm{~dB}$ passband width $\boldsymbol{B} \boldsymbol{W}_{\boldsymbol{T} 0.7} \approx 4.4 \mathrm{MHz}$.

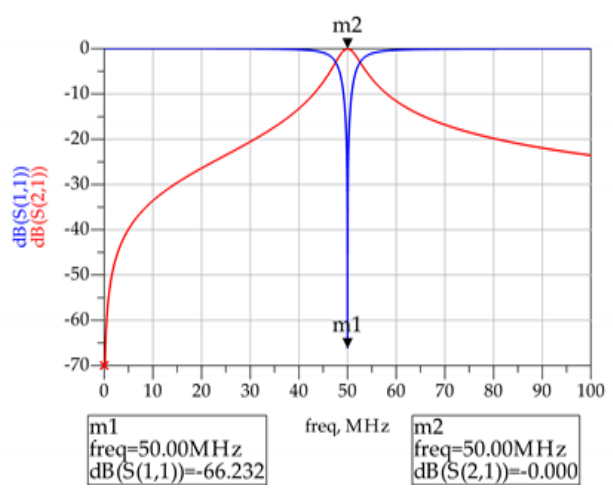

Fig.10. The simulation results of T-network.

According to the simulation experiment, the excitation circuit of ${ }^{4} \mathrm{He}$ cell is made, as shown in Fig.11(a). The ammeter is used to measure the instantaneous working current $\boldsymbol{I}_{\text {start }} \approx 1 \mathrm{~A}$ and the stable working current $\boldsymbol{I}_{\text {work }} \approx 500 \mathrm{~mA}$ respectively. Since the supply voltage is $12 \mathrm{~V}$, the instantaneous power of the circuit starting is $\boldsymbol{P}_{\text {start }} \approx 12 \mathrm{~W}$, and the power $\boldsymbol{P}_{\text {work }} \approx 6 \mathrm{~W}$ in the stable working state. NISSEI RS-70 standing-wave meter and $50 \Omega$ virtual load were used to test the actual output power, the maximum value is $\boldsymbol{P}_{\text {out }} \approx 2 \mathrm{~W}$.

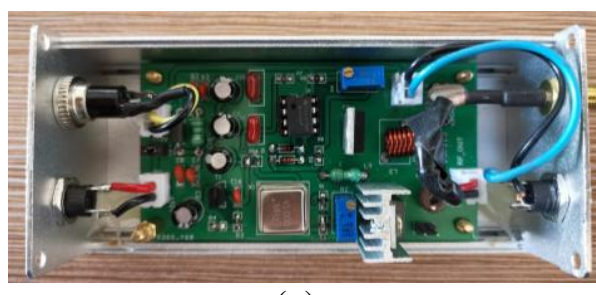

(a)

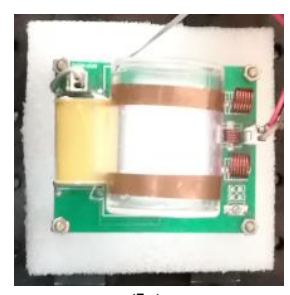

(b)
Fig.11. (a)The excitation energy source circuit. (b) ${ }^{4} \mathrm{He}$ cell has been ignited.

It can be calculated that the energy transfer efficiency of $\mathrm{HF}$ energy source is $\boldsymbol{\eta}_{\boldsymbol{P}}=2 \mathrm{~W} / 6 \mathrm{~W} \approx 33.3 \%$. Since the theoretical maximum energy transfer efficiency of class A power amplifier is $50 \%$, the energy transfer efficiency of e T-network is $\boldsymbol{\eta}_{P O}>67 \%, \boldsymbol{S}_{21}>-3.5 \mathrm{~dB}$, close to the empirical guide value $-3 \mathrm{~dB}$ for matching network design. Considering the influence of wiring trend and circuit fabrication process in circuit design, the circuit performance basically conforms to the design expectation.

\section{SIGNAL DETECTION SYSTEM}

Optically pumped magnetic sensor measurement is a closed-loop feedback regulation process. The signal detection system needs to lock the resonance point. The structure diagram of signal detection system is shown in Fig.12. Optical 
signal related to the magnetic field is converted into electrical signal by photoconverter. The electrical signal is observed trough A/D convertor transforming to digital after processing of pre-amplifier and band-pass filter. An alternating electric tuning rules [24]. The forward gain and open-loop gain settings are equal for convenient simulation of the system. and sampling rate is set as $10 \mathrm{~Hz}$.

Unit Step response simulation was carried out for the

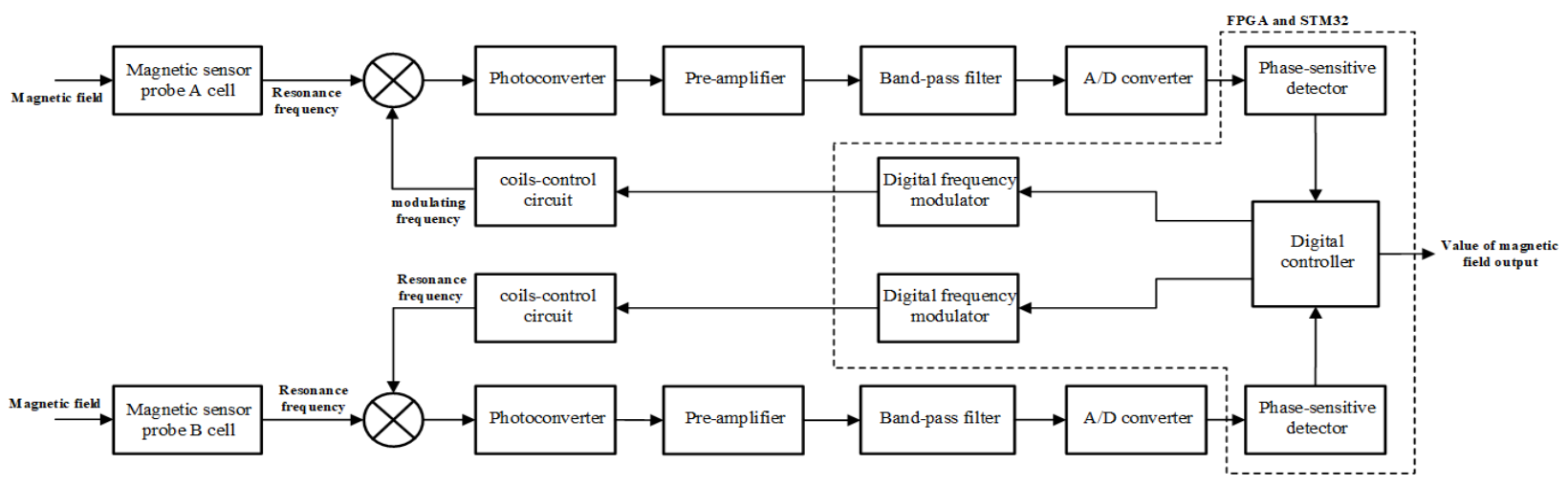

Fig. 12. The structure diagram of signal detection system.

field frequency modulator is built in FPGA, and the modulator drives the Helmholtz coils through a circuit. Modulating signal generated by the Helmholtz coils is applied to the cell, forming

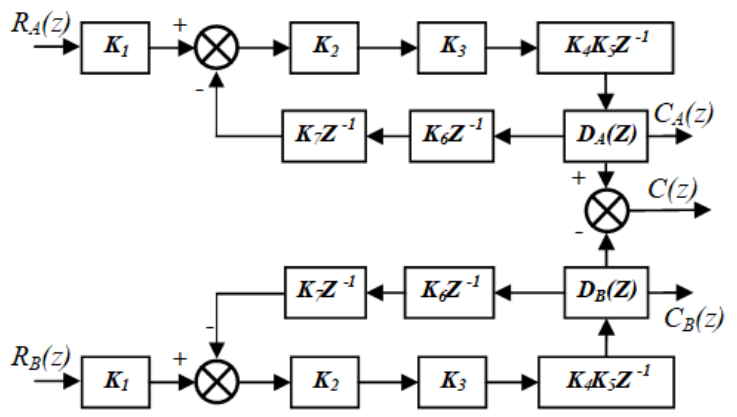

the closed-loop control of the detection system.

Fig.13. The mathematical model of signal detection system.

The mathematical model of signal detection system is shown in Fig.13. The closed-loop transfer function of the mathematical model is expressed as (15).

$$
H(Z)=\frac{K_{1} K_{2} K_{3} K_{4} Z^{-1} D(Z)}{1+K_{2} K_{3} K_{4} K_{5} K_{6} Z^{-3} D(Z)}
$$

In $(15), \boldsymbol{K}_{\boldsymbol{1}}$ is gyromagnetic ratio, $\boldsymbol{K}_{\boldsymbol{l}}=28.02356, \boldsymbol{K}_{2}$ is coefficient of photoelectric to voltage, $\boldsymbol{K}_{2}=0.9 \times 190 \times 1000, \boldsymbol{K}_{3}$ is magnification of pre-amplifier and filter, $\boldsymbol{K}_{3}=10 \times 510 \times 5, \boldsymbol{K}_{4}$ and $\boldsymbol{K}_{5}$ are amplification of $\mathrm{AD}$ convertor and phase-locked amplifier, respectively, $\boldsymbol{K}_{4}=2^{18} / 5, \boldsymbol{K}_{5}=1.3563 \times 1.8118 . \boldsymbol{K}_{\boldsymbol{6}}$ and $\boldsymbol{K}_{7}$ are coefficient of frequency modulator and coils-control circuit, respectively, $\boldsymbol{K}_{\boldsymbol{\sigma}}=(14000 \times 2 \pi \times 10) /\left(49999872 \times 2^{48}\right), \boldsymbol{K}_{7}=12 / 3.3$. Increment PID is selected and expressed as (16) [23].

$$
D(Z)=\left\lfloor K_{P}\left(1-Z^{-1}\right)+K_{I}+K_{D}\left(1-2 Z^{-1}+Z^{-2}\right)\right\rfloor\left(1+Z^{-1}\right)
$$

Where $\boldsymbol{K}_{\boldsymbol{P}}, \boldsymbol{K}_{\boldsymbol{I}}$ and $\boldsymbol{K}_{\boldsymbol{D}}$ are coefficient of proportional, integral and differential respectively. The calculation result simulated on MATLAB is obtained using Ziegler-Nichols and the results of simulation are shown in the Fig.14. It is proved that $\boldsymbol{K}_{\boldsymbol{P}}=5, \boldsymbol{K}_{I}=5, \boldsymbol{K}_{\boldsymbol{D}}=0$ is reasonable.

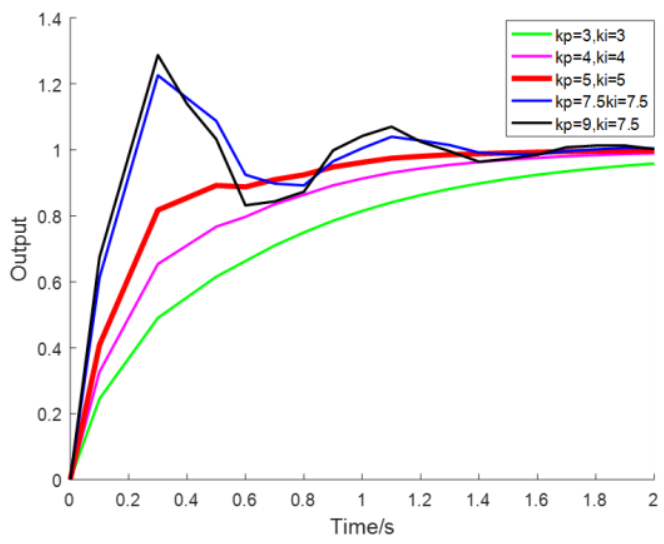

Fig.14. The simulation results of unit step response.

On the basis of PID parameters, the working process of optimized frequency modulator is simulated, and experimental results are shown in Fig.15. $\boldsymbol{c l k}$ represents the clock signal of the detection system, lia represents the obtained deviation $\boldsymbol{e}(\boldsymbol{k})$, pid_clk represents the clock signal of PID controller, delta_uk represents the frequency modulator output signal $f(k)$.

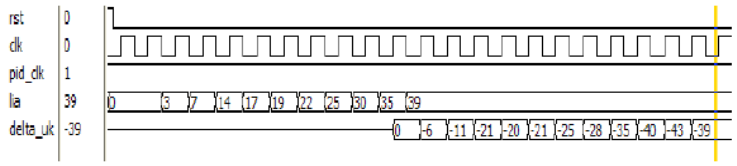

(a)

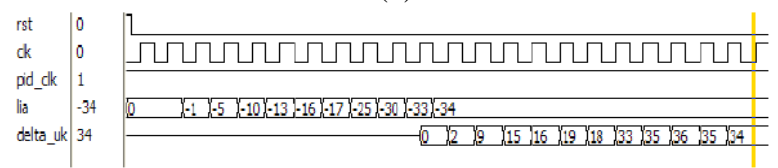

(b)

Fig.15. Simulation results of modulator (a) Deviation value is positive (b) Deviation value is negative. 
The experimental results show that the digital frequency modulator based on the increment PID method can effectively eliminate the modulation frequency and resonance frequency deviation in the signal detection process, system can lock the magnetic resonance point quickly and accurately.

\section{PERFORMANCE OF THE MAGNETIC FIELD GRADIOMETER}

\section{A. Test environment and equipment}

A theoretical "zero magnetic" space was created by a magnetic field shielding tube shown in Fig.16(a). The tube is a 6-layer structure with aluminum and magnetic conductive permalloy alloy. The attenuation of external geomagnetic field by the tube can reach about $80 \mathrm{~dB}$. Test results of magnetic environment in magnetic field shielding tube shown in Fig.16(c). The horizontal axis of Fig.16(c) is the distance between the test point and the entrance. The magnetic field fluctuation in the tube is less than $0.1 \mathrm{nT}$.

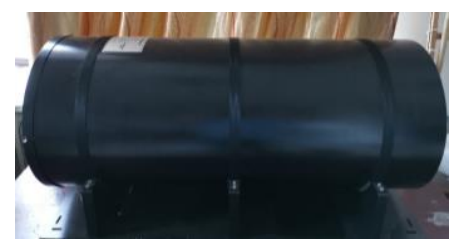

(a)

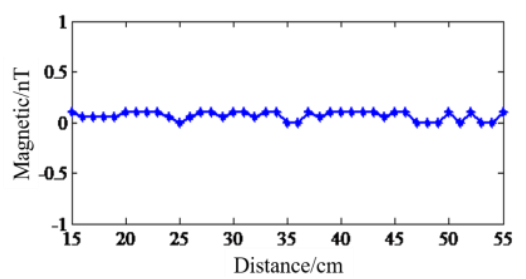

(c)

Fig. 16. (a) Magnetic field shielding tube (b) Helmholtz-Maxwell composite coils (c) Test results of magnetic environment in magnetic field shielding tube.

Helmholtz-Maxwell composite coil, are used to create different types of stable magnetic field environments in the magnetic shielding tube, as shown in Fig.16(b). The pair of coils close to each other are Helmholtz coils with a $15 \mathrm{~cm}$ radius and 217 turns. The pair far apart are Maxwell coils with $15 \mathrm{~cm}$ radius and 120 turns. The simulate results of coil's performance are shown in Fig.17.

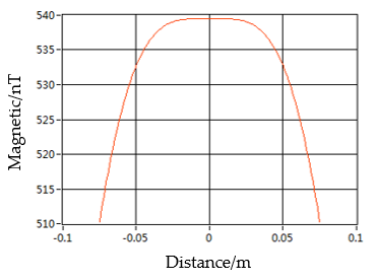

(a)

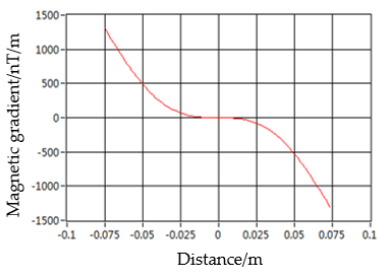

(b)

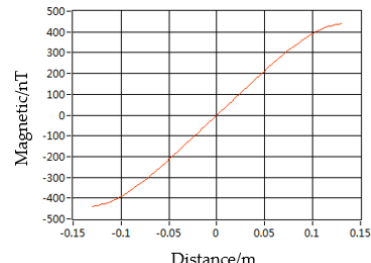

(c)

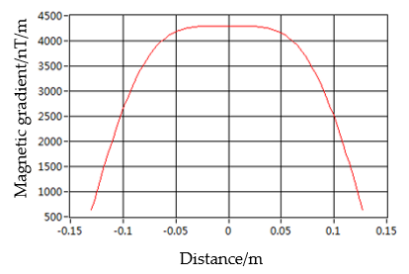

(d)
Fig.17. Helmholtz-Maxwell coils simulation results.

The horizontal axis in Fig.17(a) and Fig.17(b) shows the distance between any point along the Helmholtz coil axis and the center point. The horizontal axis in Fig.17(c) and Fig.17(d) shows the distance between any point on the axis of Maxwell coil and the center point. The vertical axis in Fig.17(a) and Fig.17(c) represents the value of the magnetic field at any point along the axis when $1 \mathrm{~mA}$ current is introduced. The vertical axis in Fig.17(b) and Fig.17(d) represents the gradient of the magnetic field of the $1 \mathrm{~mA}$ current.

According to the simulation results, the proportional coefficient of magnetic field to current in the uniform region of Helmholtz coils is about $540 \mathrm{nT} / \mathrm{mA}$, and the proportional coefficient of magnetic gradient field to current generated of Maxwell coils is about 3000nT/m@1mA.

\section{B. Sensitivity of laser ${ }^{4} \mathrm{He}$ optically pumped magnetic field sensor}

90mA current is applied to the Helmholtz coils, and the theoretical magnetic field value should be about 48600nT. According to (1), the magnetic resonance frequency is about $1.36 \mathrm{MHz}$. The frequency range of the alternating electric field was set as $0.8 \mathrm{MHz}-1.8 \mathrm{MHz}$, and the scanning period set as $1 \mathrm{~s}$. The signal sampling rate set as $1 \mathrm{k}$.

The two magnetic sensor probes are named probe A and probe B respectively. The test results are shown in Fig.18 (a) and Fig 18.(b), respectively. The solid red line and the dotted blue line represent two test results of the same probe. The horizontal axis in Fig.18 is the number of sampling points, and the corresponding scanning frequency of each sampling interval can be calculated to be about $1000 \mathrm{~Hz}$. The vertical axis in Fig.18 represents the voltage in unit $\boldsymbol{V}$.

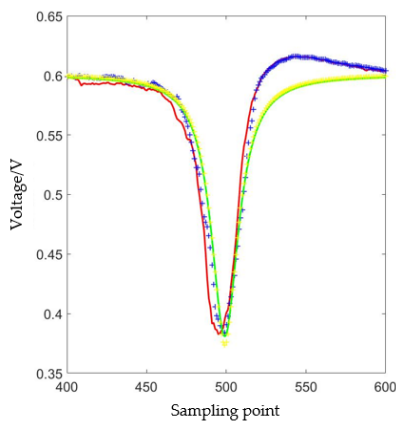

(a)

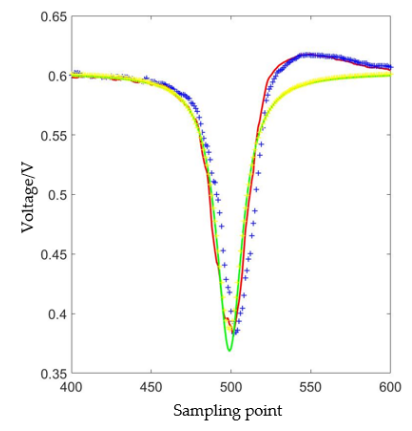

(b)
Fig. 18. (a) Resonance signal curve of Probe A. (b) Resonance signal curve of Probe B. 
Lorentz line fitting was performed on the test data. Set the fitting model as:

$$
y=a-\frac{c}{d+b x^{2}}
$$

The least square method was used to solve the model parameters. Since the model was nonlinear, the Adam gradient descent optimization method was used to solve the parameters. The number of iterations is 50000 , and the parameters are shown in TABLE II.

TABLE II. Lorentz line fitting parameters

\begin{tabular}{c|c|c|c|c|c|c}
\hline \multicolumn{2}{c|}{} & a & b & c & d & y MSE \\
\hline \multirow{2}{*}{$\begin{array}{c}\text { Probe } \\
\text { A }\end{array}$} & Data 1 & 0.6005 & 0.0136 & 0.3246 & 1.4768 & 0.00013 \\
\cline { 2 - 7 } & Data 2 & 0.6015 & 0.0161 & 0.3606 & 1.5829 & 0.00007 \\
\hline $\begin{array}{c}\text { Probe } \\
\text { B }\end{array}$ & Data 1 & 0.6020 & 0.0165 & 0.3724 & 1.5942 & 0.00005 \\
\cline { 2 - 7 } & Data 2 & 0.6033 & 0.0129 & 0.3125 & 1.4430 & 0.00007 \\
\hline
\end{tabular}

The four groups of parameters were substituted into (17), and the fitting curve was shown in Fig.19 (a) and (b). The solid green line represents the fitting curve of two groups data 1 , and the yellow dotted line represents the fitting curve of two groups data 2. Take the derivative of (17), $\Delta \boldsymbol{f}=\sqrt{\boldsymbol{d} / \mathbf{3 b}}$ and $\Delta S=c / d$. We get four groups of $\Delta f$ and $\Delta S$ are shown in TABLE III.

TABLE III. Values of $\Delta f$ and $\Delta S$

\begin{tabular}{|c|c|c|c|c|}
\hline & & $\Delta f$ & $\Delta S$ & $N$ \\
\hline \multirow{3}{*}{ Probe A } & Data 1 & $417 n T$ & $220 m V$ & $1.33 \mu V / H z^{1 / 2} @ 1 H z$ \\
\hline & Data 2 & $407 n T$ & $228 m \mathrm{~V}$ & 1.55 $\mu \mathrm{V} / \mathrm{Hz}^{1 / 2} @ 1 \mathrm{~Hz}$ \\
\hline & Average & $412 n T$ & $224 m V$ & $1.44 \mu V / H z^{1 / 2} @ 1 H z$ \\
\hline \multirow{3}{*}{ Probe B } & Data 1 & $400 n T$ & $234 m V$ & $2.11 \mu V / H z^{1 / 2} @ 1 H z$ \\
\hline & Data 2 & $428 n T$ & $217 m V$ & $1.81 \mu V / H z^{1 / 2} @ 1 H z$ \\
\hline & Average & $414 n T$ & $226 m V$ & $1.96 \mu V / H z^{1 / 2} @ 1 H z$ \\
\hline
\end{tabular}

The dynamic signal analyzer is used to test the noise power spectral density $\boldsymbol{N}$ of the signal. The two probes measure two sets of data respectively, and the results are shown in Fig. 19 (a) and (b).

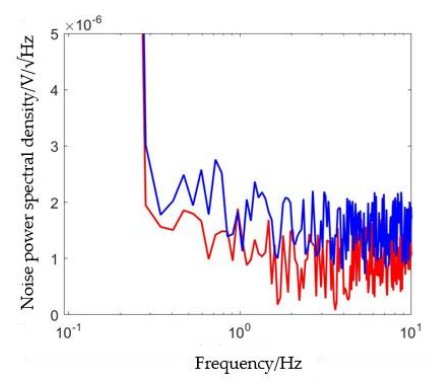

(a)

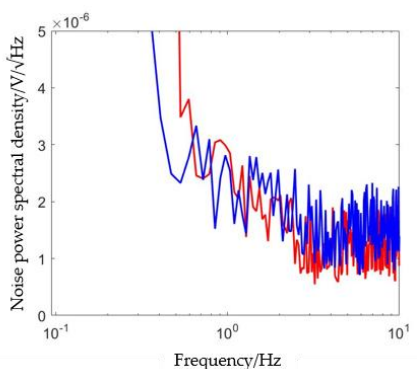

(b)
Fig. 19. (a) Noise power spectral density of Probe A. (b) Noise power spectral density of Probe B.

Probe B is higher in $N$ than probe $\mathrm{A}$ at $1 \mathrm{~Hz}$, as shown in TABLE III. The reason is that the components and welding technology of the two probes are different, and the photodiode installation has position deviation. After averaging the two sets of data, the sensitivity values of the two probes were calculated according to (2). As shown in TABLE IV.

TABLE IV. Sensitivity of two probes

\begin{tabular}{c|c}
\hline & Sensitivity $\boldsymbol{\delta} \boldsymbol{B}$ \\
\hline Probe A & $2.65 \mathrm{pT} / \mathrm{Hz} z^{1 / 2} @ 1 \mathrm{~Hz}$ \\
\hline Probe B & $3.59 \mathrm{pT} / \mathrm{Hz}^{\mathrm{I} / 2} @ 1 \mathrm{~Hz}$ \\
\hline
\end{tabular}

\section{C.Performance of gradiometer}

Place the two probes in the Helmholtz-Maxwell composite coil at the same time and install at a distance of $10 \mathrm{~cm}$. According to the parameters of coil, set the current value into the Helmholtz coil to $75 \mathrm{~mA}$, and set the current value into the Maxwell coil to increase in range of $1 \mathrm{~mA}$ to $10 \mathrm{~mA}$ with a $1 \mathrm{~mA}$ step. Theoretically, the two positions where the magnetic sensor is placed will generate a magnetic gradient field in the range of 40350-39000nT and 40650-42000nT, respectively.

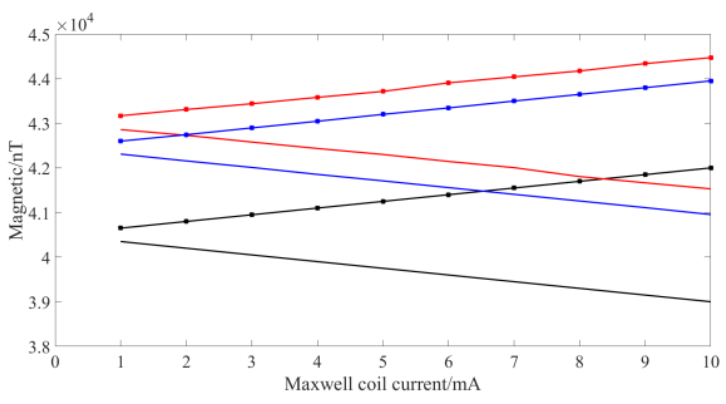

Fig.20. Data of magnetic field gradiometer and Cs-3.

As shown in Fig.20, the red solid line and red dot indicate the magnetic field values measured by the two probes of the magnetic field gradiometer, respectively. The solid blue line and the blue dots represent the magnetic field values measured by Cs-3, respectively. Solid black lines and dots represent theoretical values of magnetic fields. According to the values in Fig.20 and the installation distance of probes, the calculation results of magnetic gradient value are shown in TABLE V.

TABLE V. Magnetic gradient value comparison

\begin{tabular}{c|c|c|c}
\hline & $\begin{array}{c}\text { theoretical } \\
\text { values }\end{array}$ & $\begin{array}{c}\text { Cs-3 } \\
\text { values }\end{array}$ & $\begin{array}{c}\text { gradiometer } \\
\text { values }\end{array}$ \\
\hline $1-2 \mathrm{~mA}$ & $3000 \mathrm{nT} / \mathrm{m}$ & $3230 \mathrm{nT} / \mathrm{m}$ & $3240 \mathrm{nT} / \mathrm{m}$ \\
\hline $2-3 \mathrm{~mA}$ & $3000 \mathrm{nT} / \mathrm{m}$ & $3200 \mathrm{nT} / \mathrm{m}$ & $3220 \mathrm{nT} / \mathrm{m}$ \\
\hline $3-4 \mathrm{~mA}$ & $3000 \mathrm{nT} / \mathrm{m}$ & $3210 \mathrm{nT} / \mathrm{m}$ & $3230 \mathrm{nT} / \mathrm{m}$ \\
\hline $4-5 \mathrm{~mA}$ & $3000 \mathrm{nT} / \mathrm{m}$ & $3200 \mathrm{nT} / \mathrm{m}$ & $3210 \mathrm{nT} / \mathrm{m}$ \\
\hline $5-6 \mathrm{~mA}$ & $3000 \mathrm{nT} / \mathrm{m}$ & $3210 \mathrm{nT} / \mathrm{m}$ & $3220 \mathrm{nT} / \mathrm{m}$ \\
\hline $6-7 \mathrm{~mA}$ & $3000 \mathrm{nT} / \mathrm{m}$ & $3220 \mathrm{nT} / \mathrm{m}$ & $3230 \mathrm{nT} / \mathrm{m}$ \\
\hline $7-8 \mathrm{~mA}$ & $3000 \mathrm{nT} / \mathrm{m}$ & $3210 \mathrm{nT} / \mathrm{m}$ & $3210 \mathrm{nT} / \mathrm{m}$ \\
\hline $8-9 \mathrm{~mA}$ & $3000 \mathrm{nT} / \mathrm{m}$ & $3200 \mathrm{nT} / \mathrm{m}$ & $3200 \mathrm{nT} / \mathrm{m}$ \\
\hline $9-10 \mathrm{~mA}$ & $3000 \mathrm{nT} / \mathrm{m}$ & $3200 \mathrm{nT} / \mathrm{m}$ & $3200 \mathrm{nT} / \mathrm{m}$ \\
\hline average & $3000 \mathrm{nT} / \mathrm{m}$ & $3209 \mathrm{nT} / \mathrm{m}$ & $3218 \mathrm{nT} / \mathrm{m}$ \\
\hline
\end{tabular}

As shown in TABLE $\mathbf{V}$, the values measured by the magnetic field gradiometer and two Cs-3 are slightly larger than the theoretical values of magnetic gradient, because the 
deviation between the actual parameters of the coil and the ideal parameters caused by the manufacturing process. But, the measurement results of gradiometer and two Cs-3 are basically the same. In conclusions, the performance of the magnetic field gradiometer based on laser helium optically pumped magnetic field sensors is excellent.

\section{CONCLUSIONS}

This paper designed a magnetic field gradiometer based on laser helium optically pumped magnetic field sensors. The sensitivity of two probes was $2.65 \mathrm{pT} / \mathrm{Hz}^{1 / 2} @ 1 \mathrm{~Hz}$ and $3.59 \mathrm{pT} /$ $\mathrm{Hz}^{1 / 2} @ 1 \mathrm{~Hz}$, respectively. The comparison with Cs-3 data proves the practical performance of the magnetometer.

Based on the completed work, the magnetometer designed in this paper can be further optimized and improved to increase the number of laser beams. If the multi-channel probes under the same light source can work simultaneously, the full-axis magnetic field gradiometer with the same light source can be constructed. In addition, to ensure the quality of magnetic gradient measurement data, according to different application scenarios, magnetic compensation algorithm can be introduced into signal detection and processing system to realize real-time data preprocessing.

\section{ACKNOWLEDGMENT}

This work was supported by the Special Projects for Monitoring, Warning and Prevention of Major Natural Disasters, the National Key Research and Development Program of China 2018 (Grant No. 2018YFC1503803 and 2018YFC1503903).

\section{REFERENCES}

[1] Matzka, J.; Chulliat, A.; Mandea, M.; Finlay, C.C.; Qamili, E. Geomagnetic Observations for Main Field Studies: From Ground to Space. Space Science Reviews 2010, 155, 29-64.

[2] Ichihara S , Mizutani N , Ito Y , et al. Differential Measurement With the Balanced Response of Optically Pumped Atomic Magnetometers[J]. IEEE Transactions on Magnetics, 2016, 52(8):1-1..

[3] Zhou, Z.; Wang, C.; Ma, M.; Zeng, F.; Cheng, D.; Ji, Y. Research of control system model and design of digital controller for 4 he optically pumped magnetometer (OPM). Journal of Computational and Theoretical Nanoscience 2016, 13, 43-49.

[4] Schultze, V.; Schillig, B.; Ijsselsteijn, R.; Scholtes, T.; Woetzel, S.; Stolz, R. An optically pumped magnetometer working in the light-shift dispersed Mz mode. Sensors (Switzerland) 2017, 17,561 -

[5] Labyt E, Corsi M C, Fourcault W. Magnetoencephalography With Optically Pumped ${ }^{4} \mathrm{He}$ Magnetometers at Ambient Temperature[J]. IEEE Transactions on Medical Imaging, 2019, 38(1):90-98.

[6] Elrefai A L , Sasada I , Harada S . Gradiometer and Magnetometer Integration Using a Pair of Fundamental Mode Orthogonal Fluxgate Sensor Heads[J]. Magnetics IEEE Transactions on Magnetics, 2015, 51(11):1-4..
[7] Sheng D , Perry A R , Krzyzewski S P, et al. A microfabricated optically-pumped magnetic gradiometer[J]. Applied Physics Letters, 2017, 110:031106.

[8] Tobely T E , Salem A . Position detection of unexploded ordnance from airborne magnetic anomaly data using 3-D self organized feature map[C]// IEEE International Symposium on Signal Processing \& Information Technology. IEEE, 2006.

[9] Pärkkä, J, Ennes, M, Van Gils, M. Automatic feature selection and classification of physical and mental load using data from wearable sensors[J]. Information technology \& applications in biomedicine IEEE international conferen, 2010:1-5.

[10] Pradhan, S.; Mishra, S.; Behera, R.; Poornima; Dasgupta, K. An atomic magnetometer with autonomous frequency stabilization and large dynamic range. Review of Scientific Instruments $\mathbf{2 0 1 5}$, 86, 063104.

[11] Leger, J.-M.; Bertrand, F.; Jager, T.; Le Prado, M.; Fratter, I.; Lalaurie, J.-C. Swarm Absolute Scalar and Vector Magnetometer Based on Helium 4 Optical Pumping. Procedia Chemistry 2009, 1, 634-637.

[12] Fratter, I.; Léger, J.-M.; Bertrand, F.; Jager, T.; Hulot, G.; Brocco, L.; Vigneron, P. Swarm Absolute Scalar Magnetometers first in-orbit results. Acta Astronautica 2016, 121, 76-87.

[13] Budker D , Romalis M . Optical magnetometry[J]. Nature Physics, 2007.

[14] Savukov I, Kim Y J , Shah V , et al. High-sensitivity operation of single-beam optically pumped magnetometer in a $\mathrm{kHz}$ frequency range[J]. Measurement Science and Technology, 2017, 28:035104.

[15] Plante, M.K.; MacFarlane, D.L.; McGregor, D.D.; Slocum, R.E.; Sampson, W.M.; Brown, A.W. Generalized theory of double-resonance optical pumping of ${ }^{4} \mathrm{He}$. Physical Review A 2010, 82, 013837.

[16] McGregor, D.D. High-sensitivity helium resonance magnetometers. Review of Scientific Instruments 1987, 58, 1067-1076.

[17] Y. Gu, R. Y. Shi, Y. H. Wang. Study on sensitivity-related parameters of distributed feedback laser-pumped cesium atomic magnetometer. Acta Physica Sinica 2014, 63, 1-9.

[18] Chen Chen; Qin Jianan; Zhang Xue; Lin Jun; Wang Yanzhang. Temperature controller for DFB laser utilized in SERF atomic magnetometer. Infrared and Laser Engineering 2017, 45, 1205004.

[19] Denisova, N.; Skudra, A. High-frequency electrodeless discharges in helium. Plasma Sources Science and Technology 2004, 13, 594-599.

[20] Gan, Z. Equivalent-Ion Model of the Mixed Gas Discharge. 2012 Asia-Pacific Power and Energy Engineering Conference 2012, $1-4$.

[21] Mellinger A, Mellinger O . Breakdown threshold of dielectric barrier discharges in ferroelectrets: where Paschen's law fails[J]. IEEE Transactions on Dielectrics and Electrical Insulation, 2011, 18:43-48.

[22] Yuharu S, Kyohei S, Mohamed M, et al. Impedance Matching Antenna-Integrated High-Efficiency Energy Harvesting Circuit[J]. Sensors (Switzerland), 17:1763.

[23] Zeng X , Li Z , Wan J , et al. Embedded Hardware Artificial Neural Network Control for Global and Real-time Imbalance 
INTERNATIONAL JOURNAL OF CIRCUITS, SYSTEMS AND SIGNAL PROCESSING

Current Suppression of Parallel Connected IGBTs[J]. IEEE Transactions on Industrial Electronics, 2019:1-1.

[24] Meshram P M , Kanojiya R G . Tuning of PID controller using Ziegler-Nichols method for speed control of DC motor[C]// International Conference on Advances in Engineering, Science \& Management. IEEE, 2012. 